\begin{tabular}{|c|l|}
\hline Title & Experience based learning of Japanese IT professionals : A qual itative research \\
\hline Author(s) & Matsuo, Makoto; Wong, Christina W.Y .; Lai, Kee hung \\
\hline Citation & $\begin{array}{l}\text { The Journal of Strategic Information Systems, 17(3), 202-213 } \\
\text { https://doi.org/L0.1016/.jsis.2008.03.001 }\end{array}$ \\
\hline Issue Date & 2008.09 \\
\hline Doc URL & http://hdl.handle.net/2115/53172 \\
\hline Type & article (author version) \\
\hline File Information & Self archiving (JSIS).pdf \\
\hline
\end{tabular}

Instructions for use 


\title{
Experience-based learning of Japanese IT professionals: A qualitative research
}

\author{
Makoto Matsuo ${ }^{\text {a }}{ }^{* 1}$, Christina W.Y. Wong ${ }^{\text {b }}$, Kee-hung Lai ${ }^{c}$ \\ ${ }^{a}$ Graduate School of Business, Otaru University of Commerce, 3-5-21 Midori, \\ Otaru, Hokkaido 047-8501, Japan \\ ${ }^{\mathrm{b}}$ Institute of Textiles and Clothing, The Hong Kong Polytechnic University, Hung Hum, Kowloon, \\ Hong Kong, China \\ ${ }^{c}$ Department of Logistics, The Hong Kong Polytechnic University, Hung Hum, Kowloon, \\ Hong Kong, China
}

\begin{abstract}
Grounded in the Experiential Learning Theory and expertise research, this study examines the processes of experience-based learning, i.e., acquisition of skills and knowledge from direct experience, at different career stages of different types of IT professionals. A qualitative research method was used to compile a series of case studies on the basis of theoretical replication to answer this research inquiry. Semi-structured interviews were conducted with 10 IT consultants and 14 project managers in six Japanese IT firms. Our findings indicate that these different IT professionals have acquired different skills and knowledge from their job experiences at their different career stages. Academic and managerial implications of this study are discussed.
\end{abstract}

\section{Introduction}

The rapidly changing technologies and business environment demand comprehensive skills and knowledge of IT professionals on both the technical and managerial aspects of IT (Applegate and Elam, 1992; Grindley, 1992; Mathiassen et al., 1999). To acquire skills and knowledge, in addition to attending formal training courses, IT professionals learn from their daily jobs when dealing with different assignments and projects. Prior research on experience-based learning suggested that over $70 \%$ of individual learning can be explained by work experience (McCall et al., 1988; Morrison and Brantner, 1992; Morrison and Hock, 1986). As such, it is highly desirable for IT professionals to understand the skills and knowledge they should acquire through their work experiences at different stages of their career development (Applegate and Elam, 1992). Such understanding is also important for firms as it allows the management to (i) assign appropriate tasks to the right IT professionals, (ii) assess the IT professionals in terms of their skills and knowledge at different stages or phases of career progress, and (iii) leverage their skills and knowledge to improve firm performance.

\footnotetext{
1 One of the authors (Matsuo) participated in the research project as a member of the research committee. Interview data of this paper is based on the research report of this project (IT Skill Standard Research Committee, 2004).
} 
Despite the importance of on-the-job experiences, few studies have attempted to systematically investigate the differences in experience-based learning processes, which are defined as a series of experiences in a professional career of different IT professionals, and how these processes might be associated with their prior on-the-job experiences and career stages. Our literature review reveals that there are several research gaps. First, prior studies were limited to investigating the types of knowledge and skills needed by IT professionals as a result of evolving changes in IT development, business environment, and the role of IT in an organization (e.g., Benamati et al., 1997; Lee et al., 1995).

Second, although past studies have acknowledged the growing importance of IT-related intellectual and human resources in managing IT activities (e.g., Applegate and Elam, 1992; Lee et al., 1995; Thoms and Pinto, 1999), they provide limited insights on the IT professionals' skills and knowledge needed at different career stages to ensure a match between their job assignments and experiences.

Third, from the human resources management perspective, the IT literature is confined to investigating how organizations manage IT professionals by instituting a variety of human resources management practices, such as job design, performance appraisal, training, and their outcomes (Agarwal and Ferratt, 2001; Ferratt et al., 2005; Huselid, 1995; Igbaria et al., 1994; Tan and Igbaria, 1994). Yet, these studies have yielded limited managerial insights with regard to the on-the-job experience of IT professionals and how the on-the-job experience contributes to their career development.

The objective of this study is to examine the processes of accruing on-the-job experience as well as the acquired skills and knowledge by IT professionals at their different career stages within the theoretical framework of experiential learning. Understanding experience-based learning processes of different IT professionals can help provide insights to expound theories and methods for researchers and managers to improve the performance of IT professionals.

The paper is organized as follows: the next section describes the job characteristics of IT professionals, experience-based learning, expertise research, and community-of-practice in the literature. Next, we highlight the limitations of past research, identify the research gap on the experience-based learning of IT professionals, and develop a research proposition. This is followed by the details of our empirical data collection and analysis for testing the proposition of this study. Lastly, we discuss the results, academic and managerial implications, and limitations of this study.

\section{Literature review}

\subsection{Job characteristics of IT project managers and consultants}

Based on the literature, we investigated the processes of IT project managers and IT consultants in acquiring job-related skills and knowledge for a number of reasons. First, the business focus of IT firms has shifted from providing IT applications for support of customers' business operations, to delivering value-added services to their customers (Roberts et al., 2000). In providing such service, project managers and consultants are responsible not only for providing IT solutions, but also for the project outcomes in terms of project, service, and economic success (Soh et al., 1992). Second, project managers and consultants assume different roles in IT firms according to their responsibilities and job characteristics (Webber and Torti, 2004). Such differences motivate us to capture the changes in their skills and knowledge which they acquired from their work experiences. Third, due to differences in their job characteristics and responsibilities, IT project managers and consultants are likely to participate in different projects throughout their career. Their project experiences provide us with insights to identify the processes in which they acquired the knowledge and skills at their 
different career stages. Therefore, IT project managers and consultants are considered appropriate as the informants for this study.

Different types of IT professionals require a different set of skills and knowledge as they conduct different tasks which involve different responsibilities. For example, IT project managers are responsible for planning and delivering project-related tasks within a specific time frame and budget. Specifically, they handle administrative tasks ranging from setting deadlines, monitoring progress, ensuring project completion within budget, to motivating project team members, and supervising subordinates (Pavett and Lau, 1983; Webber and Torti, 2004). In other words, IT project managers perform such functions as visionaries, technical experts, motivators, team builders, negotiators, and sales people (Thoms and Pinto, 1999). They are required to master technical skills, such as understanding the operating processes, tools, and techniques, as well as the people skills, such as providing vision and direction, resolving issues, evaluating and mitigating risks, and building and sustaining client relationships (Webber and Torti, 2004). In serving their clients' IT needs, IT project managers interact with their clients on a daily basis, and in some cases, they may reside on clients' sites to understand the client needs, and to test and implement solutions. In sum, IT project managers play an external role as a client-relationship builder, and an internal role as a supervisor for an IT project team.

On the other hand, IT consultants possess a breadth of experiences in identifying problems, generating alternative solutions, resolving problems, analyzing information requirements, implementing plans, developing IT applications, and so forth. They are often hired as advisers for firms lacking internal IT expertise (Berggren et al., 2001; Nevo et al., 2007; Soh et al., 1992). In evaluating the business processes and developing IT solutions for their clients, IT consultants are expected to identify problems and suggest solutions for their clients to improve performance (Berggren et al., 2001).

\subsection{Experience-based learning}

As the literature shows, over $70 \%$ of individual learning can be explained by work experience (McCall et al., 1988; Morrison and Brantner, 1992; Morrison and Hock, 1986). The Experiential Learning Theory suggests that learning derives from experience and requires interplay between a person and his/her environment (Kayes, 2002; Kolb, 1984). It offers a theoretical ground to explain the association between an individual's skills and knowledge, and his/her job experiences (Sims, 1993).

While learning is concerned with the acquisition of knowledge and skills, experience-based learning refers to acquiring knowledge and skills from one's experiences. In line with this, Kolb $(1984)^{2}$ suggested that learning is a process where knowledge is created through the transformation of experience. He has proposed a four-stage cyclical model, which consists of the following four stages of experiential learning: (i) concrete experience, (ii) reflective observation, (iii) abstract conceptualization, and (iv) active experimentation. The immediate personal experience forms the basis for observation and reflection, which can be assimilated into abstract hypotheses or concepts, guiding learners to create new experiences. In addition to this view, Dixon (1999) argued that learning is about interpreting one's experience, which affects his/her actions. Following this line of research, experience-based learning of IT professionals raises their capability to leverage on work experiences to perform appropriately for their future job assignments.

\footnotetext{
2 Although Kolb's model of experiential learning is influential in a number of professional areas (Yamazaki and Kayes, 2004), it suffers from theoretical limitations (Kayes, 2002). Reynolds (1999) viewed that the model promotes a largely individualized perspective on the learning process at the expense of social and political influences. Holman et al. (1997) criticized that Kolb's model is biased towards the cognitive nature of learning without due regard to the learning process.
} 
Prior empirical research on experience-based learning has focused on the 'concrete experience' stage of Kolb's (1984) learning model, and investigated the characteristics of work experiences that facilitate a manager's professional development. Davies and Easterby-Smith (1984) found that managers develop their abilities when they are confronted with novelty that forces them to accept major changes in their perspectives. Similarly, McCall (1998) and McCall et al. (1988) suggested that developmental experiences fall into four different 'concrete experiences': (i) taking up different job assignments (e.g., new IT applications development, supervising project/task force, and managing projects with different scopes), (ii) playing different roles (e.g., supervisors and role models), (iii) experiencing hardships (e.g., business mistakes, career setback, subordinate performance problems, jobs changing, and distress), and (iv) doing other tasks (e.g., personal development through coursework). Based on a similar view, Skipper and Bell (2006) found that well-experienced project managers would have many years of project management working experience. Focusing on the "concrete experience" stage, prior studies seem to have a consensus that managers learn from their job experiences (McCall, 1998; McCauley et al., 1994).

\subsection{Expertise research}

Expertise research can be useful for understanding the experience-based learning process of IT professionals at their different career stages. The expertise research literature suggested approximately 10 years of active involvement in the related experiences is necessary for an individual to reach an international level of achievement (Ericsson, 1996, 1999; Ericsson et al., 1993; Simon and Chase, 1973). Ericsson (1996) has called this phenomenon the 10-year rule of necessary preparation, which suggests that a person needs at least 10 years of active involvement on a job to attain a reasonably good performance level. However, 10 years of work experience do not necessarily guarantee achievement of good performance. A number of recent reviews have found that the amount and quality of deliberate practice is related to achieving good performance outcomes (Ericsson, 1996, 1999; Ericsson and Lehmann, 1996). Deliberate practice refers to structured training activities that include well-defined tasks with a certain level of difficulty, informative feedback, and opportunities for repetition and error correction (Ericsson, 1996). Similarly, Burton et al. (1984) proposed to create 'increasingly complex microworlds', in which a learner is exposed to a sequence of environments where his or her tasks become increasingly complex, for the learner to learn complex skills. As such, an individual can learn complex skills effectively from step-by-step experience under an increasingly complex task environment. In line with this proposal, Dreyfus and Dreyfus (1987) suggested a five-step model describing the process of becoming an expert and these steps include: (i) novice, (ii) advanced beginner, (iii) competent, (iv) proficient, and (v) expert. The novice would start from knowing nothing to being able to make a reasonable attempt at performing the skill, while an expert has a deep understanding on both the task situations and responses.

Cicmil (2006) applied Dreyfus and Dreyfus's (1987) model to explain that (i) the novice learns generalized rules through a given problem and situation; (ii) advanced beginners understand the importance of the situation context; (iii) competent performers can prioritize elements of the situation by learning from their own experience and from others, (iv) proficient performers know of the interpretation and judgment involved in decision-making in addition to performing logical and analytical problem solving; and (v) an expert understands the situation intuitively and holistically. In sum, the five-step model and the 10-year rule of expertise (Ericsson, 1996) provide useful theoretical frameworks in explaining the experience-based learning processes of IT professionals. 


\subsection{Community-of-practice and knowing}

There is an epistemological divergence in the literature between positivists emphasizing measurement and constructionists stressing the uniqueness of meaning systems (Easterby-Smith et al., 1998). The constructionists emphasize the role of community-of-practice, and they advocate that work practice and learning need to be understood in terms of the communities that emerge (Brown and Duguid, 1991). In line with this, some constructionists, e.g., Lave and Wenger (1991), have doubts on the knowledge transfer models that isolate knowledge from practice. They argued that learning is a social construction, where learners construct their understanding out of various experiences (Brown and Duguid, 1991). Similarly, Cook and Brown (1999) reasoned that knowing is a part of action and knowledge is a tool of knowing. The production of new knowledge does not lie in an exploitation of tacit and explicit knowledge, but rather in an interaction with the world using knowledge. These studies suggest the importance of community-of-practice in organizational learning.

Using these studies as theoretical ground, King and Ranft (2001) studied the thoracic surgery certification process and examined how surgeons develop their knowledge through surgical operations and practices. Similarly, Orlikowski (2002) revealed that global product development of companies could generate and sustain knowledge through practices. Based on these previous studies, we advance the knowledge of experience-based learning by investigating how different types of IT experts acquire different job-related skills and knowledge through their work experiences over time.

\subsection{Proposition}

As different IT professionals have different job responsibilities and characteristics, they would acquire different sets of skills and knowledge through learning from their work experience. As such, different IT professionals accumulate different skills and knowledge at different career stages when they are assigned to different new tasks, which reflect different processes of experience-based learning from their job experience (Hall and Nougaim, 1968; Berlew and Hall, 1966; Kram and Isabella, 1985; Cicmil, 2006; Dreyfus and Dreyfus, 1987; Ericsson, 1996). We therefore posit that

Proposition: There exist different experience-based learning processes for different IT professionals at their different career stages.

\section{Research methodology}

As this research is exploratory in nature, we applied a qualitative research method to examine our research inquiry. Cresswell $(1994,1998)$ classified a qualitative method into five types: biography, ethnography, grounded theory, case study, and phenomenology. Among these types, we used the grounded theory approach (Glaser and Strauss, 1967; Strauss and Corbin, 1990), which allows us to develop a theory that is closely related to the context of the phenomena being studied (Cresswell, 1998). Such an approach is particularly appropriate for this study as the Grounded Theory approach recommends data collection driven by concepts derived from the evolving theory rather than a preconceived theoretical framework. This study lacks a theoretical explanation on the specifics of experience-based learning of different IT professionals at their different career stages. The grounded theory approach allows this to be examined in greater depth, providing insights on the career development of IT professionals.

IT professionals, namely IT project managers and IT consultants, were selected as the 
sampling frame of this study due to their critical role in developing IT solutions and providing services to customers (Roberts et al., 2000), which affect the success of IT projects (Soh et al., 1992). Moreover, IT project managers and consultants display different job responsibilities and characteristics (Webber and Torti, 2004), which enable them to acquire skills and knowledge from their work experiences. It is reasonable to assume they can provide information about experience-based learning in the context of the IT profession.

Our primary source of data came from in-depth interviews with IT professionals in six IT firms in Japan, which were identified and contacted through Japan's Ministry of Economy, Trade, and Industry (METI). These firms were purposely identified to ensure that our case samples (i) possessed large enough capital to employ experienced project managers and consultants, and (ii) invested and engaged in developing professionals. These sample firms were the leading IT companies in Japan. They delivered computing solutions to business enterprises and the government with the number of employees ranging from 1130 to 35,090 (20,950 on average), and annual revenues of US\$ 180 million to US\$25,819 million (US\$ 14,519 million on average).

We conducted interviews with 24 IT professionals of six IT firms, including 10 IT consultants and 14 IT project managers. This is consistent with the recommended sample size for exploratory research purposes (Yin, 1994). In developing our sample, we aimed to interview a wide diversity of participants to evaluate the job characteristics of IT professionals at their various career stages. For example, it is crucial to select IT project managers and consultants who have participated in various projects. In the meantime, we selected firms that have multiple IT professionals who have worked in the same job category, i.e., IT project managers or consultants, to allow theoretical replications. Consequently, we invited a number of skilled and high-performing IT project managers and consultants, with work experience ranging from 18 to 35 years, to participate in this study. Half of the consultants progressed from project managers in the early stage.

An interview protocol was developed and used to guide our interviews. The interview questions were composed of three sections. In the first section, we asked the participants to introduce themselves, and describe their job nature and company background. In the second section, we asked the participants to describe their job experiences, such as the projects they have completed and their roles in these projects, in their early (first 5 years), middle (from 6 to 12 years), and latter (over 13 years) career stages. The objective of this section was to ensure the participants considered their past job experiences and were prepared to identify the skills and knowledge they have acquired from their work experiences. In the third section, we asked the participants to describe the skills and knowledge they have acquired at their different career stages and to provide examples from the specific experiences. The purpose of this section is to identify the relationship of the acquired skills and knowledge related to their work experience.

The interviews lasted $70 \mathrm{~min}$ on average. All interviews were tape-recorded and transcribed. We used a grounded theory approach for data analysis (Glaser and Strauss, 1967; Strauss and Corbin, 1990). Specifically, we (i) compared the interview data collected from any two participants to generate theoretical properties of the acquired skills and knowledge and work experience at each career stage, (ii) compared the interview data of another participant to the theoretical properties generated in step one, (iii) reduced the list of properties for coding to formulate a smaller and higher-conceptual set of theoretical properties, and (iv) repeated steps (i) to (iii) until no new property of the acquired skills and knowledge and the work experiences emerged (Glaser and Strauss, 1967).

Based on these generated theoretical properties, we used grounded theory coding (i.e., open, axial, and selective coding) to identify the associations of the properties of the acquired skills and knowledge as well as the job experiences at different career stages. To ensure the 
robustness of our findings, we applied the techniques of triangulation by collecting documentations from our site visits and comparing them with our interview data. In addition, we asked our informants to review our case report for factual verification.

\section{Results}

\subsection{Categories of skills, knowledge, and experience}

The categories of experience and acquired skills were derived from our interview data during open and axial coding. In coding the interview data, we focused on the relevance and importance of the data in answering our research inquiry rather than on the frequency of which they were reported (Lyles and Mitroff, 1980). We linked the categories of experience with those of acquired skills and knowledge for each of the career stages. Table 1 displays the categories of acquired skills and knowledge, namely customer relationship skills (e.g., communication with customers), management skills relating to the task group (e.g., motivating and directing members), job-related knowledge (e.g., knowledge of technology), and analytical skills (e.g., problem solving).

The job experiences that are important for acquiring job-related skills and knowledge were composed of four categories, which are shown in Table 2. These categories of job experiences were assessed in terms of task difficulty or success of the associated sub-categories. For example, in the 'task characteristics' category of experience, 'partial job as a system engineer' and 'sub-leader of a small project' were considered relatively easy tasks. 'Leader of a small or mid-sized project' was regarded as a moderately difficult task, while 'leader of a large or difficult project' is an extremely difficult task. Moreover, 'zero-based experience' refers to the experience of a person who has never done such tasks before, and 'single-handed experience' means doing a task without assistance from others.

Table 1 Categories of skills and knowledge

\begin{tabular}{|c|c|}
\hline Category & Sub category \\
\hline Customer relationship skills & $\begin{array}{l}\text { Communicating with customers } \\
\text { Building relationships with customers } \\
\text { Understanding customers' problems } \\
\text { Trouble-shooting }\end{array}$ \\
\hline Group management skills & $\begin{array}{l}\text { Clarifying priority and deciding promptly } \\
\text { Motivating and directing team members } \\
\text { Making out a schedule for the tasks } \\
\text { Managing members by controlling sub-leaders }\end{array}$ \\
\hline Analytical skills & $\begin{array}{l}\text { Problem solving } \\
\text { Logical thinking } \\
\text { Using analytical methods }\end{array}$ \\
\hline Job-related knowledge & $\begin{array}{l}\text { Knowledge of business process } \\
\text { Knowledge of technology } \\
\text { Knowledge of management } \\
\text { Knowledge of manufacturing and service processes }\end{array}$ \\
\hline
\end{tabular}


Table 2 Categories of experience

\begin{tabular}{|c|c|}
\hline Category & Sub category \\
\hline Role models & $\begin{array}{l}\text { Bad example } \\
\text { Good example }\end{array}$ \\
\hline Interacting with customers & $\begin{array}{l}\text { Contacting with customers } \\
\text { Learning from customers } \\
\text { Working with customers } \\
\text { Interacting with tough customers }\end{array}$ \\
\hline Task characteristics & $\begin{array}{l}\text { Special tasks } \\
\text { Partial job as a system engineer } \\
\text { Sub-leader of a small project } \\
\text { Leader of a small or mid-sized project } \\
\text { Leader of a large or difficult project } \\
\text { Single-handed experience } \\
\text { Zero-based experience }\end{array}$ \\
\hline Results of task & $\begin{array}{l}\text { Failure } \\
\text { Success and achievement }\end{array}$ \\
\hline
\end{tabular}

Table 3 Importance of acquired skills and knowledge

\begin{tabular}{lcccc}
\hline & \multicolumn{4}{c}{ Acquired skills and knowledge } \\
\cline { 2 - 5 } & $\begin{array}{c}\text { Customer } \\
\text { relationship skills }\end{array}$ & $\begin{array}{c}\text { Group } \\
\text { management skills }\end{array}$ & $\begin{array}{c}\text { Analytical } \\
\text { skills }\end{array}$ & $\begin{array}{c}\text { Job-related } \\
\text { knowledge }\end{array}$ \\
\hline Project managers & +++ & +++ & ++ & ++ \\
Consultants & +++ & + & ++ & ++ \\
\hline $\begin{array}{l}+++ \text { : strongly emphasized } \\
\text { ++: emphasized } \\
\text { +: moderately emphasized }\end{array}$ & & & & \\
\hline
\end{tabular}

There were similarities and differences in the responses given by IT consultants and project managers with respect to the relative importance of skills and knowledge. Table 3 shows these differing managerial emphases in terms of the categories of the acquired skills and knowledge. Experience, acquired skills, and knowledge of IT project managers and consultants in the three career stages (early, middle, and latter stage) are shown in Fig. 1.

Both IT consultants and project managers felt that customer relationship skills were necessary to perform their jobs, although they placed different levels of emphases on different sub-categories of customer relationship skills. For example, IT project managers focus on acquiring skills for communicating with customers and trouble-shooting, while IT consultants direct their efforts on building relationships with customers and understanding customer's problems. One IT consultant commented:

We play several roles as consultants. One important role is to speak on behalf of our 
client in his/her firm, and to organize our client's ideas. I believe that identifying and examining our clients' problems from a different point of view and putting them in writing is our job.

This suggests that consultants need to possess the skills to build relationships with clients and to recognize their tacitlyheld problems. In contrast, project managers are required to clarify clients' expectations and priorities, as suggested by a project manager:

Clients demand many things. We need to understand them precisely. If we misunderstand them, they will turn us away at their door. It does not work if you grasp their needs roughly. We should have a clear image of a client's needs. Just doing what they want is not enough. We have to evaluate what they are saying from different angles to understand their true needs.

With regard to job-related knowledge, our findings show similar emphases between IT consultants and project managers. Both professionals acquire skills and knowledge of technology at an early career stage, with project managers emphasizing the knowledge of manufacturing and service processes and consultants stressing the knowledge of business processes and management.

Our findings also suggest that IT project managers stress more group management skills than that of IT consultants. One IT project manager commented:

The number of team members one can directly manage is four or five, so it is necessary to find key people; these key people would include someone who is technologically proficient, as well as someone who is skilled at managing people. As a project manager, I can manage the project by controlling these key team members who, in turn, supervise the system engineers working on location.

In contrast to project managers, consultants placed emphasis on analytical skills for problem solving and making propositions. One consultant explained his methodology of identifying the root causes of problems:

First of all, we write down the problems on post-it cards, and then classify them into similar groups, in order to understand the structure of the problems. This step involves identifying cause-effect or hierarchical relationships between the problems systematically by arranging the cards in a chart. Using this chart, we determine the major problems. Then, we explore why and how things are happening in the way they do, in order to find the root causes of the problems.

\subsection{Processes of experience-based learning}

The experience-based learning process is defined as a series of experiences in a professional's career in this study. As shown in Fig. 1, common experience-based learning processes of IT consultants and project managers include 'partial job as a system engineer' and 'sub-leader of a small project' in the early career stage, 'a leader of a small or mid-sized project' in the middle career stage, and 'a leader of a large or difficult project' and 'interacting with tough customers' in the latter career stage.

The main differences between the experiences of IT consultants and project managers are in the early and middle career stages. IT consultants tend to engage in 'special tasks' and 'contact with customers' in the early career stage, and 'zero-based experience' or 'single-handed experience' in the middle career stage. A consultant explained his experience 
in the early stage:

I used to be a system engineer of Decision Support Systems (DSS) and worked with researchers from MIT for the developments. I interacted closely with the staffs in the strategic planning and accounting departments, instead of those in the IT department. This experience has been very helpful in providing consulting services in my latter career."

Project Managers

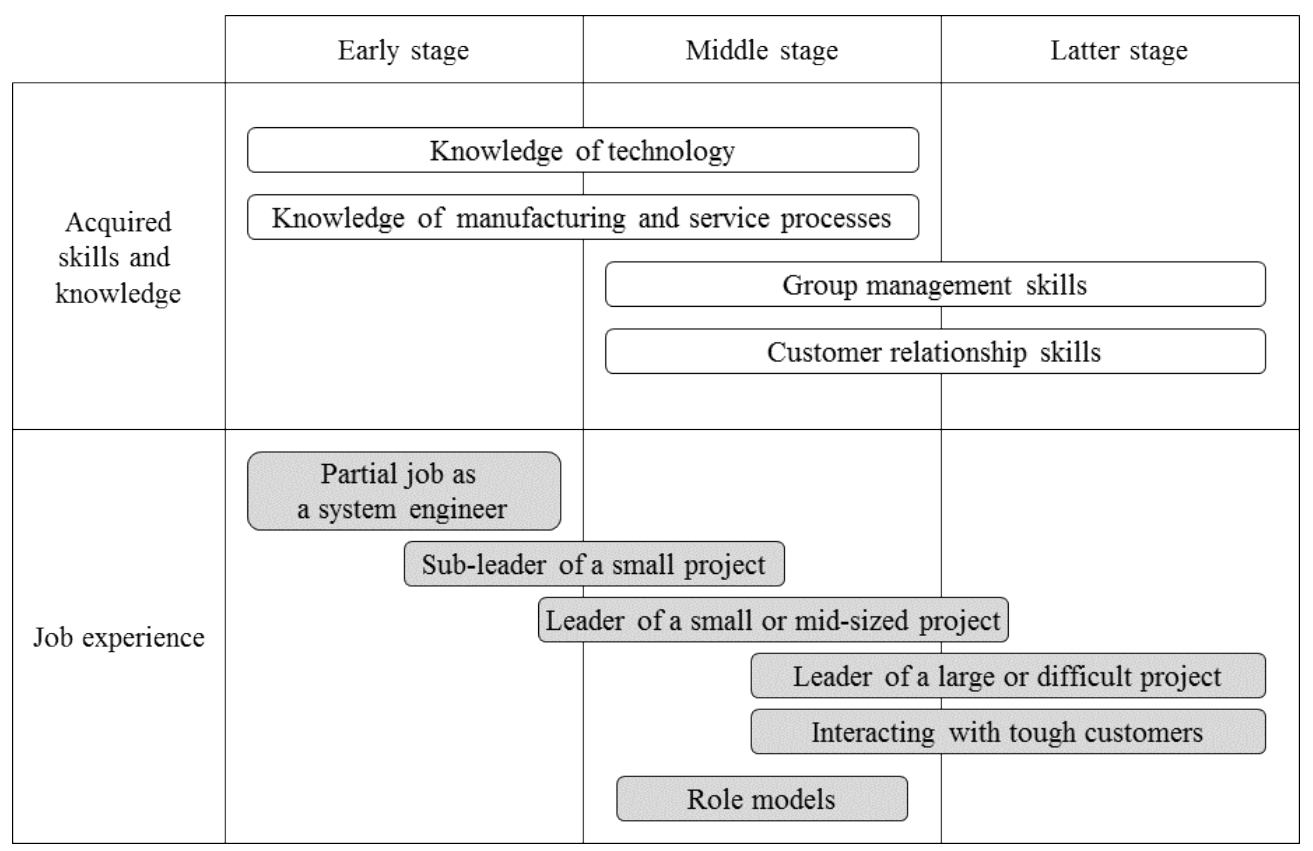

\section{Consultants}

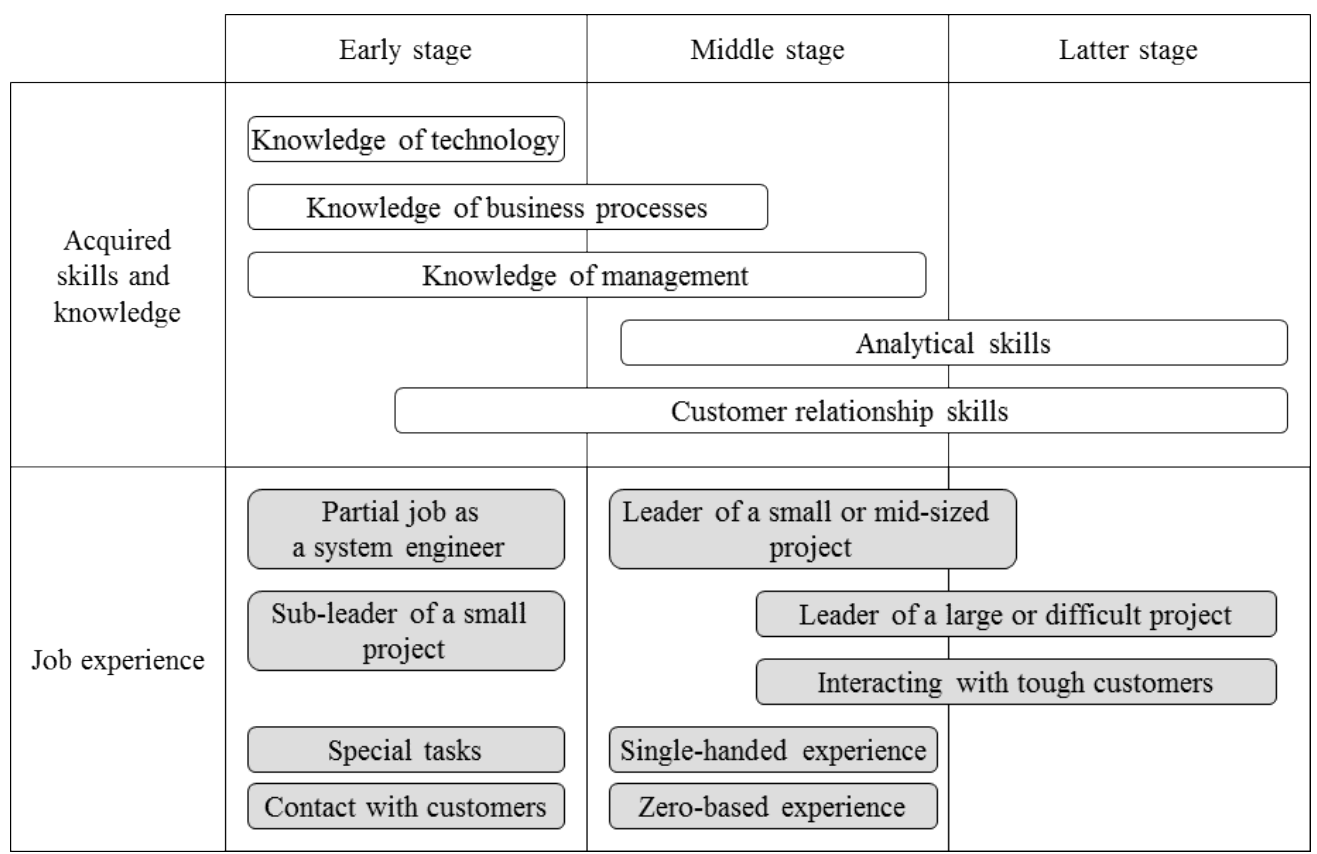

Fig. 1. Experience and acquired skills of project managers and consultants at different career stages. 
One consultant described a 'zero-based experience' at his middle career stage:

We developed application software for customers in the business of retail and distribution. We started from zero when developing a customer-membership system for a department store. Following this, we set out to develop a POS (point of sales) system in the same store. As the store deals with various products (clothing, food, and furniture), I learned about the various departments in developing the POS system. When the department store started adding new services like insurance and ticket reservations, I needed to learn new technologies, such as databases; I also needed to develop new knowledge with respect to ticket operations and tax systems.

Another consultant gained experience working in a small software firm, where she gained confidence in her technical skills through working on new projects:

It was hard for me, as I was doing something no one had done before. Today, everyone knows how to use a network, but at that time, only a few people knew how to use a UNIX machine connected with a LAN as a substitute of a mainframe. I mainly worked and tackled problems with the trial-and-error approach. By completing the project by myself, I gained confidence in my technical capability.

These comments suggest that consultants tend to acquire knowledge through participating in projects, which they have had no experience of before, and accomplished difficult projects without assistance. On the contrary, project managers seem to acquire skills and knowledge through step-by-step experiences, where they can apply their previously learned skills and knowledge in their latter projects. A project manager remembered a job experience in his early career stage:

After joining this firm, I worked for the department in charge of financial companies as a system engineer for about 5 years. In these 5 years, I learned the structure of information systems and acquired basic skills as a system engineer. I did not belong to a big group, but was part of a small group consisting of three to five people.

Many project managers worked as a sub-leader or leader of a small or medium sized project in the middle career stage. One project manager commented:

At the middle career stage, I played the role of project leader in a team of 30-40 system engineers. I was responsible for understanding the client's needs, as some clients stress system performance, whereas other clients are more concerned about system reliability. I was also responsible for communicating and prioritizing our clients' needs.

A project manager, who worked on a large and difficult project with a tough client, described his experience as follows:

It was a multi IT vendor project and the clients were very demanding. They told us they wanted to use the system at close to maximum capacity, so we did not have any surplus capacity left in the system. Clients do not bear any errors in the systems during implementation. Another major problem of this project was it involved 120-150 team members. It was very difficult to supervise all of them. As a project leader, I can only indirectly manage the team through subleaders. 
These comments indicate that project managers acquire knowledge in stages through their experience by working on progressively larger and more difficult projects. One project manager explained the nature of project management in this way:

As project leaders have many responsibilities, managing a large project at an early stage in one's career can sometimes result in a loss of confidence if one fails. I believe that it is better for one to manage small projects in the beginning, which involves less than 20 team members, and then progress to managing bigger projects.

Similarly, another manager stressed the importance of gradually increasing task difficulty:

It is important to assign young employees to work on tasks $10-20 \%$ above the level of difficulty of their previous tasks. Good project leaders should assign tasks to employees that are beyond employees' current capabilities for them to develop.

In addition to the step-by-step experience, several project managers learned from their bosses or others in their middle career stage, while no consultants described such experience. One project manager commented:

I have no experience of failure as a project leader. However, among the projects that I was asked to assist, several failed badly. Being able to see what caused such failure was a good experience for me.

Another project manager explained that there was a role model in the following way.

I was supervised by a senior project manager of my firm, who was an expert in operating systems. I learned a lot from him by observing his behavior at work and I was greatly influenced by him.

This indicates that project managers tend to acquire knowledge and skills through apprenticeship training or in community of practice, while consultants tend to learn by themselves. Our results suggest that the acquired skills and knowledge, and the experience-based learning processes are different among the consultants and project managers in different career stages. This lent support to the existence of different experience-based learning processes for different IT professionals at their different career stages.

\section{Discussion}

\subsection{Theoretical implications}

Our case companies show that IT consultants and project managers exhibit different experience-based learning processes. The interview results indicate that IT project managers acquire skills and knowledge by means of step-by-step experiences, advancing through increasingly difficult tasks. On the other hand, consultants acquire skills and knowledge through performing an array of tasks at different career stages (e.g., acquiring both analytical skills and customer relationship skills at the middle and latter career stages through being leaders of projects and working on zero-based projects).

This study points to the need for further work on the roles of job experience and career stage in experience-based learning, as the learning process from job experience varies among job types and career stages. Consistent with previous research (Glaser and Chi, 1988), this study suggests that the experience-based learning process depends on specific task 
characteristics and career stages.

We identified differences in the experience-based learning process between IT consultants and project managers, especially during the mid-career stage, though both IT professions require similar experiences for the acquisition of basic knowledge of technology in the early career stage. This corresponds to King and Ranft's (2001) finding that disciplined thought with respect to foundational knowledge in a field is necessary before going on to build new and specialized knowledge.

As shown in Fig. 2, IT project managers acquire skills and knowledge gradually through step-by-step experience, progressing from easy to difficult tasks, which is shown as a linear function in Fig. 2. This is consistent with the 'increasingly complex microworlds' proposal of Burton et al. (1984), which proposed the importance of designing a learning environment in which individuals can learn skills in progression to master complex skills. In contrast, consultants learn through difficult tasks, such as zero-based or single-handed experiences, after mastering basic skills and knowledge. They display a non-linear function in their experience-based learning process over the years, as displayed in Fig. 2.

Results suggest that project managers learned through legitimate peripheral participation (Lave and Wenger, 1991), where they participated in minute and superficial yet necessary tasks that contribute to the community in the early stage, and their participation gradually takes forms that are more and more central to the functioning of the community in the middle and latter stages.

It should be noted that project managers often learned from role models (e.g., supervisors), while consultants reported little experience of learning from others. This suggests that project managers tend to learn in communities of practice (Lave and Wenger, 1991; Wenger et al., 2002), in which junior members acquire knowledge and skills through apprenticeship training (Brown et al., 1989).

The differences in experience-based learning processes between IT consultants and project managers may be due to differences in their skills and responsibilities. As a project manager's objective is to complete projects on time within a given budget, group management skills become necessary for managing their subordinates with different roles and skills involved in a project to ensure the projects can be completed on time and within budget. On the other hand, a consultant's objective is to solve problems, which require analytical skills for problem solving. Experiencing highly difficult tasks with ill-defined problems (Glaser and Chi, 1988) is useful to improve IT consultants' ability to analyze and solve problems.

We should also note that consultants perform 'special tasks' and 'contact with customers' in their early career stage. Such experiences enable consultants to gain knowledge in a specific field and to acquire skills to build relationships with customers.

Moreover, although past research suggests that managers learn from challenging jobs which force them to accept major changes in their perspectives (Davies and Easterby-Smith, 1984; McCall, 1998; McCall et al., 1988), our findings indicate that experience-based learning depends on job types and career stages.

Although there are differences in the acquired skills and knowledge and job experiences between IT project managers and consultants, their experience-based learning process in the early stage of their careers are similar. Both types of IT professionals acquired job-related knowledge (e.g., knowledge of technology) through experiencing 'partial job as a system engineer' and 'sub-leader of a small project' in the first five years of their career. This suggests that the early experience of system engineer or sub-leader of small projects serves as a basis for their career development regardless of the nature of their tasks.

In addition, due research attention should be paid to the interpretation of experience rather than to the work experience itself. Kolb (1984) defined individual learning as a process whereby knowledge is created through the transformation of experience. With regard to the 
role of experience in developing knowledge, Dixon (1999) has suggested that learning is about interpreting experiences, which mediates actions. Fig. 1 suggests that even when IT consultants and project managers have similar work experiences, they acquire different skills from their work experience.

\section{Project managers}

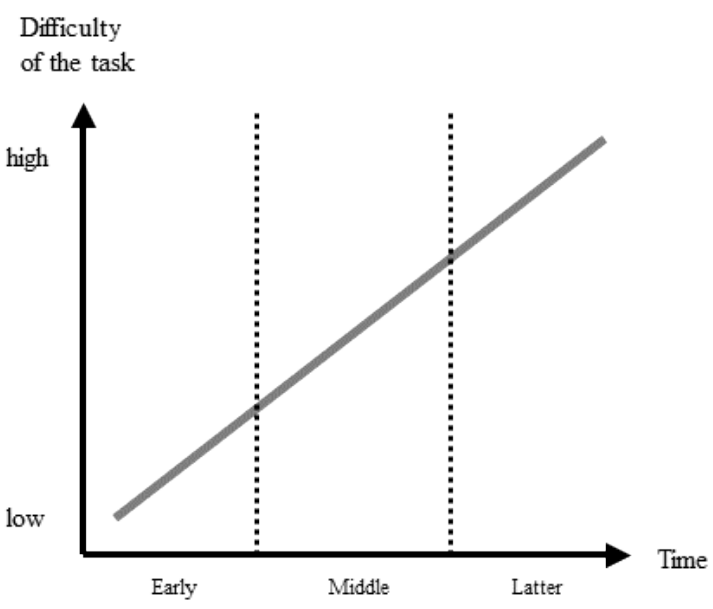

Consultants

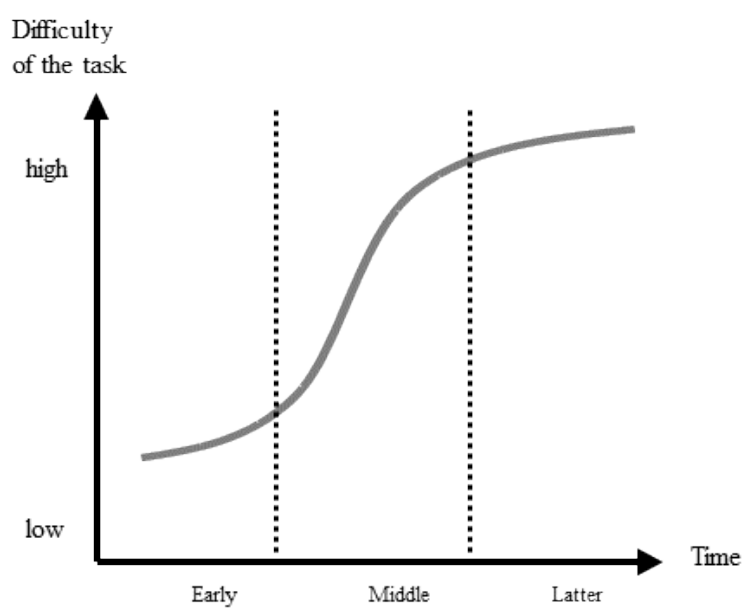

Fig. 2. Difference in learning process between project managers and consultants.

\subsection{Practical implications}

This study has a number of important practical implications for IT professionals. In particular, they should recognize the experience-based learning process for different job types in their career development. The training experienced by our subjects indicates that development of IT project managers benefit from step-by-step experience and apprenticeship training, while IT consultants can develop their job abilities through zero-based or single-handed experiences.

Moreover, IT professionals should understand that different job types exhibit different experience-based learning processes. For example, project managers displayed sophisticated group management skills, while consultants demonstrated analytical skills. However, it should be noted that customer management skills are important for both types of IT professionals. They should recognize the on-the-job experience that enables them to acquire skills and knowledge for their career development.

\subsection{Limitations and future research}

This study is exploratory in nature and has a number of limitations that are worthy of future research. First, this study did not examine the influence of organization on individual learning. In the future, we may study how executives manage IT professionals by creating an organizational structure to build and nurture communities-of-practice (Thompson, 2005), and investigate the nature of learning organizations (Senge, 1990) that support the communities-of-practice of IT professionals.

Second, our data were mainly collected through interviews, and relied heavily on self-reported experience and acquired skills and knowledge confined to a limited sample of IT companies. Noting that it is difficult to collect data on the learning activities over time or to obtain objective data about the job experience and the acquired skills and knowledge of IT professionals, we had little choice but to rely on interview data collected from a limited 
number of organizations. However, we made efforts to reduce biases through the use of interview protocols and data triangulations, which were useful to enhance the reliability of our findings.

Third, the results of this study may have been influenced by national culture and industry structure. Since many Japanese firms have adopted lifetime employment systems, most respondents have no experience of working with another employer. Chia (2003) has argued that the learning process differs substantially between western and eastern cultures. A cultural comparison of experience-based learning would be an interesting topic for future research.

Finally, little information could be found on the effect of communities of practice on knowledge acquisition. Few consultants commented that they were influenced by the community to which they belong. There may be two reasons for this result: (i) high-achievers tend to learn on their own rather than relying on their colleagues or supervisors, (ii) respondents were unable to recognize the influence of community on their knowledge acquisition. In line with these, Brown and Duguid (2001) have pointed out that there is still little knowledge on the practical implications of community of practice. The role of community of practice should be further explored in future research on experience-based learning.

\section{Acknowledgements}

The authors are grateful to the constructive comments from two anonymous reviewers on earlier versions of this paper. The second author was partially supported by The Hong Kong Polytechnic University under Grant No. 4-ZZ69. The third author of this paper was supported in part by The Hong Kong Polytechnic University under Grant No. 1-BB7N.

\section{References}

Agarwal, R., Ferratt, T.W., 2001. Crafting an HR strategy to meet the need of IT workers. Communications of the ACM 44 (7), 58-64.

Applegate, L.M., Elam, J.J., 1992. New information systems leaders: a changing role in a changing world. MIS Quarterly 16 (4), 469-490.

Benamati, J.S., Lederer, A.L., Singh, M., 1997. Changing information technology and information technology management. Information \& Management 31 (5), 275-288.

Berggren, C., Soderlund, J., Anderson, C., 2001. Clients, contractors, and consultants: the consequences of organizational fragmentation in contemporary project environments. Project Management Journal 32 (3), 39-48.

Berlew, D.E., Hall, D.T., 1966. The socialization of managers: effects of expectations on performance. Administrative Science Quarterly 11, 207-223.

Brown, J.S., Duguid, P., 1991. Organizational learning and communities-of-practice toward a unified view of working, learning, and innovating. Organization Science 91 (2), 40-57.

Brown, J.S., Duguid, P., 2001. Knowledge and organization: a social-practice perspective. Organization Science 12 (2), 198-213.

Brown, J.S., Collins, A., Duguid, P., 1989. Situated cognition and the culture of learning. Educational Researcher 18 (1), 32-42.

Burton, R.R., Brown, J.S., Fischer, G., 1984. Skiing as a model of instruction. In: Rogoff, B., Lave, J. (Eds.), Everyday Cognition: Its Development in Social Context. Harvard University Press, Cambridge, MA.

Chia, R., 2003. From knowledge-creation to the perfecting of action: Tao, Basho and pure experience as the ultimate ground of knowing. Human Relations 56 (8), 953-981.

Cicmil, S., 2006. Understanding project management practice through interpretative and critical research perspectives. Project Management Journal 37 (2), 27-37. 
Cook, S.D.N., Brown, J.S., 1999. Bridging epistemologies: the generative dance between organizational knowledge and organizational knowing. Organization Science 10 (4), 381400.

Cresswell, J.W., 1994. Research Design: Qualitative and Quantitative Approaches. Sage, CA.

Cresswell, J.W., 1998. Qualitative Inquiry and Research Design: Choosing Among Five Traditions. Sage, CA.

Davies, J., Easterby-Smith, M., 1984. Learning and developing from managerial work experiences. Journal of Management Studies 21 (2), 169-183.

Dixon, N., 1999. The Organizational Learning Cycle: How We can Learn Collectively, 2nd ed. Gower Press, Aldershot.

Dreyfus, H.L., Dreyfus, S.E., 1987. Mind Over Machine: The Power of Human Intuition and Expertise in the Era of the Computer. Free Press, NY.

Easterby-Smith, M., Snell, R., Gherardi, S., 1998. Organizational learning: diverging communities of practice? Management Learning 29 (3), 259-271.

Ericsson, K.A., 1996. The acquisition of expert performance: an Introduction to Some of the Issues. In: Ericsson, K.A. (Ed.), The Road to Excellence. Lawrence Erlbaum Associates, Mahwah, NJ.

Ericsson, K.A., 1999. Creative expertise as superior reproducible performance: innovative and flexible aspects of expert performance. Psychological Inquiry 10 (4), 329-333.

Ericsson, K.A., Lehmann, A.C., 1996. Expert and exceptional performance: evidence of maximal adaptation to task constraints. Annual Review of Psychology 47, 273-305.

Ericsson, K.A., Krampe, R.T., Tesch-Romer, C., 1993. The role of deliberate practice in the acquisition of expert performance. Psychological Review 100 (3), 363-406.

Ferratt, T.W., Agarwal, R., Brown, C.V., Moore, J.E., 2005. IT human resource management configurations and IT turnover: theoretical synthesis and empirical analysis. Information Systems Research 16 (3), 237-255.

Glaser, R., Chi, M.T.H., 1988. Overview. In: Chi, M., Glaser, R., Farr, M.J. (Eds.), The Nature of Expertise. Lawrence Erlbaum Associates, Mahwah, NJ.

Glaser, B., Strauss, A., 1967. The Discovery of Grounded Theory. Aldine, Chicago, IL.

Grindley, K., 1992. Information systems issues facing senior executives: the culture gap. Journal of Strategic Information Systems 1 (2), 57-62.

Hall, D.T., Nougaim, K., 1968. An examination of Maslow's need hierarchy in an organizational setting. Organizational Behavior and Human Performance 3 (1), 12-35.

Holman, D., Pavlica, K., Thorpe, R., 1997. Rethinking Kolb's theory of experiential learning: the contribution of social constructivism and activity theory. Management Learning 28, $135-148$.

Huselid, M.A., 1995. The impact of human resource management practices on turnover, productivity, and corporate financial performance. Academy Management Journal 18 (2), 635-672.

Igbaria, M., Meredith, G., Smith, D., 1994. Predictors of intention of IS professionals to stay with the organization in South Africa. Information \& Management 26 (5), 245-256.

IT Skill Standard Research Committee, 2004. Research report of Japanese IT skill standard research committee (2002 Research sponsored by Ministry of Economy, Trade, and Industry). In: Kenji Hirata (Ed.), Japan Information Processing Development Corporation, Japan Information-Technology Engineers Examination Center.

Kayes, D.C., 2002. Experiential learning and its critics: preserving the role of experience in management learning and education. Academy of Management Learning and Education 1 (2), 137-149.

King, A.W., Ranft, A.L., 2001. Capturing knowledge and knowing through improvisation: what managers can learn from the thoracic surgery board certification process. Journal of 
Management 27, 255-277.

Kolb, D.A., 1984. Experiential Learning: Experience as the Source of Learning and Development. Prentice Hall, New Jersey.

Kram, K.E., Isabella, L.A., 1985. Mentoring alternatives: the role of peer relationships in career development. Academy of Management Journal 28 (3), 110-132.

Lave, J., Wenger, E., 1991. Situated Learning: Legitimate Peripheral Participation. Cambridge University Press, Cambridge, MA.

Lee, D.M.S., Trauth, E.M., Farwell, D., 1995. Critical skills and knowledge requirements of IS professionals: a joint academic/industry investigation. MIS Quarterly 19 (3), 313-340.

Lyles, M.A., Mitroff, I.I., 1980. Organizational problem formulation: an empirical study. Administrative Science Quarterly 25, 102-119.

Mathiassen, L., Borum, F., Pedersen, J.S., 1999. Developing managerial skills in IT organizations: a case study based action learning. Journal of Strategic Information Systems 8 (2), 209-225.

McCall, M.W., 1998. High Flyers: Developing the Next Generation of Leaders. Harvard Business School Press, Boston, MA.

McCall, M.W., Lombardo, M.M., Morrison, A.M., 1988. The Lessons of Experience: How Successful Executives Develop on the Job. The Free Press, NY.

McCauley, C.D., Ruderman, M.N., Ohlott, P.J., Morrow, J.E., 1994. Assessing the developmental components of managerial jobs. Journal of Applied Psychology 79 (4), 544-560.

Morrison, R.F., Brantner, T.M., 1992. What enhances or inhibits learning a new job? A basic career issue. Journal of Applied Psychology 77 (6), 926-940.

Morrison, R.F., Hock, R.R., 1986. Career building: learning from cumulative work experience. In: Hall, D.T. et al. (Eds.), Career Development in Organizations. Jossey-Bass, San Francisco, 236-273.

Nevo, S., Wade, M.R., Cook, W.D., 2007. An examination of the trade-off between internal and external IT capabilities. Journal of Strategic Information Systems 16, 5-23.

Orlikowski, W.J., 2002. Knowing in practice: enacting a collective capability in distributed organizing. Organization Science 13 (3), 249-273.

Pavett, C.M., Lau, A.W., 1983. Managerial work: the influence of hierarchical level and functional specialty. Academy of Management Journal 26 (1), 170-177.

Reynolds, M., 1999. Critical reflection and management education: rehabilitating less hierarchical approaches. Journal of Management Education 23, 537-553.

Roberts, J., Miles, I., Hull, R., 2000. Introducing the new service economy. In: Brigitte Andersen et al. (Eds.), Knowledge and Innovation in the New Service Economy. Edward Elgar, Cheltenham, England.

Senge, P.M., 1990. The Fifth Discipline: The Art \& Practice of the Learning Organization. Doubleday/Currency, NY.

Simon, H.A., Chase, W.G., 1973. Skill in chess. American Scientist 61, 394-403.

Sims, R.R., 1993. Evaluating public sector training programs. Public Personnel Management. 22 (2), 243-255.

Skipper, C.O., Bell, L.C., 2006. Influences impacting leadership development. Journal of Management in Engineering 22 (2), 68-74.

Soh, C.P.P., Yap, C.S., Raman, K.S., 1992. The career decision of information systems people. Information \& Management 24 (1), 23-32.

Strauss, A., Corbin, J., 1990. Basics of Qualitative Research. Sage, Newbury Park.

Tan, M., Igbaria, M., 1994. Technology and remuneration of information technology professionals in Singapore. Information \& Management 26 (4), 219-229.

Thompson, M., 2005. Structural and epistemic parameters in communities of practice. 
Organization Science 16 (2), 151-164.

Thoms, P., Pinto, J.K., 1999. Project leadership: a question of timing. Project Management Journal 30 (1), 19-26.

Webber, S.S., Torti, M.T., 2004. Project managers doubling as client account executives. Academy of Management Executive 18 (1), 60-71.

Wenger, E., McDermott, R., Snyder, W.M., 2002. Cultivating Communities of Practice: A Guide to Managing Knowledge. Harvard Business School Press, Boston, MA.

Yamazaki, Y., Kayes, D.C., 2004. An experiential approach to cross-cultural learning: a review and integration of competencies for successful expartriate adaptation. Academy of Management Learning and Education 3 (4), 362-379.

Yin, R.K., 1994. Case Study Research: Design and Methods, 2nd ed. Sage, Thousand Oaks, CA. 